\title{
I. Researches respecting the composition of enamel
}

\section{Clouet}

To cite this article: C. Clouet (1800) I. Researches respecting the composition of enamel , Philosophical Magazine Series 1, 7:25, 3-17, DOI: 10.1080/14786440008677241

To link to this article: http://dx.doi.org/10.1080/14786440008677241

曲 Published online: 18 May 2009.

Submit your article to this journal $\pi$

Џ Article views: 2

Q View related articles $\sqsubset$ 


\title{
THE
}

\section{PHILOSOPHICAL MAGAZINE.}

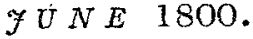

1. Refearcbes refpecting the Compofition of Enamel. By C. Clovet, A pociate of the Frencb National Infitute*.

WHITE ENAMEL.

W Hite enamel, either for earthen-ware, or the purpofe of being applied on metals, is compofed in the following manner: You firt calcine a mixture of lead and tin, which may be varied in the following proportions; viz. for 100 parts of lead, 15, 20, 30, and even 40 of tin. A mixture of lead and tin calcines very eafly in contact with the air. As foon as this mixture is brought to a red heat, nearly a cherry colour, it burns like charcoal, and is calcined very fpeedily. The compofition which calcines beft, is that which in 100 pounds of lead contains from 20 to 25 of tin. The tin here meant is pure tin. In proportion as the calcination is effected, you muft take out the calcined part, and continue to oxydate the reft until the whole has become pulverulent. As fome fmall particles always efcape calcination, you muft expofe to the fire a fecond time the oxyd obtained in order to calcine it completely; which may be eafily known by its ceafing to fparkle; that is to fay, when you no longer fee any parts burn like coal, and when the whole appears of an uniform colour. When the proportion of tin exceeds 25 or 30 , a ftronger fire is neceffary to produce the calcination. In a word, by varying the degrees of heat you will be able

* From the Ainales de Cbimie.

$\mathrm{B} 2$ 
to difcover that beft fuited to the mixture on which you operate.

A hundred parts of the calx above mentioned; which in the French potteries is called calcine, is generally taken with 100 parts of fand. From 25 to 30 pounds of fea-falt, or muriat of foda, are added: the whole is well mixed together, and it is fufed in the bottom of a furnace in which potter's ware is baked. This matter is generally placed on fand, on lime quenched in the open air, or on afhes. The bottom of the mafs is in general badly fufed. This, however, does not prevent the matter, after it has been pounded, and applied on the articles, from becoming exceedingly white and hard in the furnace. When taken from the furnace it is not white; it is even often very black: in general it is marbled with black, gray, and white.

This procefs is that generally ufed in potteries. In the compofitions deftined for earthen-ware, the proportion of 25 parts of tin to 100 of lead is never exceeded: for common carthen-ware, the manufacturers are even fatisfied with ${ }_{5}$ of tin to roo of lead. It may be eafily feen, that if you winh to obtain an enamel whiter and more fufible, you muft diminifh the quantity of fand; but there is no neceffity for augmenting that of the fea-falt, or muriat of foda; as the whitenefs and opacity depend on the quantity of tin, you may ufe calcine, which contains 25 or 30 per cent. For example, roo of fuch calcine, 60 of fand, and 25 of marine falt, give a compofition exceedingly fufble.

But it is to be obferved, that it is necefiary to employ fome further manipulations when you with to have enamel proper for being applied on metal, and are defrous to give it all the perfection of which it is furceptible. In that cafe, you do not employ crude fand, but calcine it, in a ftrong heat, with a quarter of its weight of marine falt, either in a fmall quantity in a crucible, or on a large fcale in a potter's furnace. If you wifh to have as very fufible enamel, you may even add minium, or lead calcined by the former operation, and nearly. as much fea-falt, that is to fay, a fourtb. You then obtain. a white mafs half fufcel and porous, which you pulverife, and employ in the compofition of enamel inftead of fand, and in 
the fame proportions as fand: you may even diminifh the quantity of this matter to $5 \circ$ per cent. if you are defirous to obtain an enamel very fufible. This will depend alfo on the calcine employed; for that which is moft charged with tin is the leaft fufible.

When you wifh to have fluxes for the colours, you employ the fame compofitions before mentionéd, except that you put little or no tin irrto the learl. In the latter cafe you muft generally employ minium. This flux is good for certain colours, but not for all. There are fome which become tarnifhed by fluxes, that contain the oxyds of lead. In that cafe, you muft make fluxes without oxyd of lead. Nitre and borax are generally ufed for making this glafs, but you add no calx of tin. The following are thofe which I have tried:

Three parts of filiceous fand, one of chalk, and three of calcined borax, give a matter proper to be ufed as a flux for purples, blues, and other delicate colours.

Three parts of white or flint glafs, one of calcined borax, a quarfer of a part of nitre, one of the white oxyd of antimony made with nitre well wafhed, give an exceedingly white enamel, which may ferve alfo as a flux for purple, and particularly for blue.

Sixty parts of enamel fand or less, thirty of alum, thirtyfive of fea-falt, and a hundred of minium, or any other oxyd of lead, give a white enamel when the fluxes do not predominate too much, and a gelatinous glafs when a great deal of fluxes has been added. This glafs is good for red, and the enamel may be applied to all kinds of clay capable of fuftaining a ftrong heat.

It is of great importance to remark, and to know, that the fand employed for enamel muft not be fand which contains only filex : fand of that kind alone is of no ufe. The fand proper for this purpofe is that which contains talc with filex. To make a fand proper for enamel and the fluxes of colours, \& cc. there mutt be nearly one part of talc and three of filiceous fand.

What appears to me moft effential in regard to the fuccefs of enamel, is the choice of fand, It is very polible to com- 
pofe this fand by art; and though I have not decompoled it, I have found by fynthefis, that three parts of filiceous fand and one of talc form an excellent fand for enamel. From this it may be readily feen, that, to compofe with facility fand for enamel, nothing is neceffary but to determine, by a good analyfis, the quantity of talc. This fand may be procured in places where earthen-ware is made. It may be eafily known; for, befides the filiceous fand, which forms the greateft part of it, you may obferve in it talcky particles in great abundance; and, to be good, it muft contain nearly a quarter. When it does not contain a fufficient quantity, the enamel it produces fufes with more difficulty, and does not become fmooth; it remains granulated and pitted. There are certainly fome combinations of earth which may produce very good fluxes, either for enamel or for tranfparent colours. It might be attended with advantage to try fome of thefe combinations. Ponderous earth (barytes) and lime fufe very well together: by adding a little filex, or a little magnefia, it is probable that an excellent matter might be produced. If this glafs, compofed of lime and barytes only, had fufficient folidity to refift the air and weak acids, there would be no neceffity perhaps to add filex; but if the marine falt, as I am inclined to think, ought alfo to enter into the compofition of this kind of glafs, flex ought likewife to form a part of it. The experiments on this head, for the fake of trial, may be varied different ways. When the glafs deftined to ferve as fiux for colours is employed, it is cuftomary, in order that they may be rendered more fufible, to add a little nitre and borax. The common borax of the thops contains an excefs of foda, which, in my opinion, it would be of benefit to faturate with the nitric acid. I think alfo that the flux might be rebalsed with the dole of nitre and borax, or of nitric borax, which might be added before being employed. It is only to colours fuch as purple and the oxyd of cobalt that nitre and borax are added.

I have rried to find a fubftitute for marine falt in the compofition of white enamel. Potarh produced only an ugly and ill fured gray mals, which acquired no luftre in the fur nace; nitre produced a green mafs, but exceedingly friable; 
fulphat of potafh produced very nearly the fame effect, only the mais was a little whiter: but neither of thefe enamels was worth any thing. I did not try pure foda: I have, however, heard common foda extolled; but as it contains a great deal of marine falt, it muft undoubtedly be on account of this falt that it produces a good effeet. Pure.foda may neverthelefs be tried, either alone or, with marine falt; it perhaps might produce no bad effect with potath.

I have tried alfo a mixture of equal parts of lime and argil, to which I added one part of filex, and likewife without filex; but this mixture did not fupply the place of talcky fand. This fand is not in general found in grains; it exhibits itfelf moft commonly under the form of a ftone, fuch as free-ftone; but fome of it is found alfo in grains.

We fhould be much deceived in making white enamel were we to employ the oxyds of tin and lead feparately, as I have read in all the authors I could find who treat on the art of pottery. None of them fay what they ought refpecting enamel, nor even refpecting the compofition or nature of the carth proper for bearing an enamel.

It is effential that the lead and tin for making the oxyd deflined to produce white enamel, fhould be fufed and mixed together before they are calcined; and if you wifh that the enamel fhould immediately acquire its full whitenefs, it will be requifite that the calcination fhould be complete.

Bifmulh might perhaps be employed as a fubfitute for the lead, and it is not improbable that it would give a good product. Bifmuth allo might be mixed with the lead in the following manner; wiz. one part of lead, one of bifmuth, and one of tin: or other proportions might be employed; but I have not tried any others. As the oxyd of bifmuth, however, is exceedingly fufible, I think it might be admitted, with great advantage, into certain fluxes. I have not tried what might be produced by the white calx of zinc, nor by that of tin, made by diffolving it in the nitric acid or by detonation with nitre. A mixture of lead and tin, detonated with nitre, would be ufeful. Though the white calx of regulus of antimony made by nitre, and well wafhed, (diaphoretic antimony,) produces a very beautiful white enamel when 
fufed with three parts of white glafs, (which contains neither lead nor other metallic oxyds, ) and one of glafs of borax, with a half or fourth part of nitre; yet this calx, fo white when mixed with the compofition of enamel, made with enamel fand and the combined oxyd of lead and tin, inftead of increafing, tarnithes the whitenefs, and only gives a blueifh enamel of a livid colour*. Perhaps enamels, completely made and mixed together in the firt inftance, would not produce the fame effect; but this I never tried. I have, however, employed this compofition as a flux for colours, which, applied afterwards on the enamel of earthen-ware, nreferved its beauty. I put fome of this pure enamel alfo. aver that of earthen-ware, and I think it preferved its whitenefs.

The principal quality of good enamel, and that which renders it fit for being applied on baked earthen-ware, or on metals, is the facility with which it acquires luftre by a moderate heat, (a cherry-red heat, more or lefs, according to the nature of the enamel,) without entering into complete fufion t. Enamels applied to earthen-ware and metals poffefs this quality. They do not enter into complete fufion; they affume only the ftate of pafte, but of a pafte exceedingly firm; and yet when baked one might fay that they had been completely fufed.

There are two methods of painting on enamel : on raw or on baked enamel. Both thefe methods are employed, or may be employed, for the fame object. Solid colours, capable of fuftaining the fire neceffary for baking the enamel ground, may be applied in the form of fufed enamel on that which is raw, and the artift may afterwards finith with the tender colours. The colours applied on the raw material do not require any fux; there is one, even, to which filex muft be added, that is, the calx of copper, which gives a very

* Antimony, employed in any manner as a glazing for earthen-ware, would be more dangerous than lead; even the latter fhould, if pofible, be difearded. -Epir.

+ The ingenious author has omitied another principal quality. It ought never to contain fuch a portion of deliquefcing falts, as to endanger its being afterwards injured by water. This takes place oftener than is generally fufpected.-EDIr. 
beautiful green: but when you wifh to employ it on the raw material, you muft mix with it about two parts of its weight of filex, and bring the mixture into combination by means of heat. You afterwards pulverife the mafs you have thus obtained, in order to employ it.

To obtain good white enamel, it is of great importance that the lead and tin thould be very pure. If thefe metals contain copper or antimony, as is often the cafe, the enamel will not be beautiful: iron is the leaft hurtful.

\section{OF COLOURED ENAMELS.}

All the colours may be produced by the metallic oxyds. Thefe colours are more or lefs fufed in the fire, according as they adhere with more or lefs ftrength to their oxygen. All metals. which readily lofe their oxygen cannot endure a great degree of heat, and are unfit for being employed on the raw material.

\section{Purple.}

This colour is the oxyd of gold, which may be prepared different ways; as by precipitating, by means of a muriatic fulution of tin, a nitro-muriatic folution of gold much diluted in water. The leaft quantity poffible of the folution of tin will be fufficient to form this precipitate. The folution of tin muft be added gradually until you obferve the purple colour begin to appear: you then ftop; and having fuffered the colour to be depofited, you put it into an earthen veffel to dry flowly*. The different folutions of gold, in whatever manner precipitated, provided the gold is precipitated in the ftate of an oxyd, give always a purple colour, which will be more beautiful in proportion to the purity of the oxyd; but neither the copper nor filver, with which gold is generally found allayed, injure this colour in a fenfible manner: it is changed, however, by iron. The gold precipitate which gives the moft beautiful purple is certainly fulminating gold, which lofes that property when mixed with fluxes. Purple is an abundant colour; it is capable of bearing a great deal of flux, and in a fmall quantity communicates its colour to a great deal of matter. It appears that faline fluxes are better fuited

- The colour is always more beautiful, if the precipitate is ground with the flux before it has become dry.-EDir.

VOL. VII. 
to it than thofe in which there are metallic calces. Thore, therefore, which have been made with filex, chalk, and borax, or white glafs, borax, and a little white oxyd of antimony, with a little nitre, as I have already mentioned, ought to be employed with it. Purple will bear from four to twenty parts of flux, and even more, according to the fhade required. Painters in enamel employ generally for purple a flux which they call brilliant white. This flux appears to be a femiopake enamel, which has been drawn into tubes, and afterwards blown into a ball at an enameller's lamp. Thefe bulbs are afterwards broken in fuch a manner that the flux is found in fmall fcales, which appear like the fragments of fmall hollow fpheres. Enamel painters mix this flux with a little nitre and borax. This matter, which produces a very good effeet, I employed, without attempting to decompofe it. It may be a very fufible common white enamel which has been blown into that form. It is to be remarked, that purple will not bear a ftrong heat.

\section{Red.}

We have no metallic oxyd capable of giving directly a fuffed red; that is to fay, we have no metallic calces which, entering into fufion, and combining under the form of tranfparent glafs with fluxes or glafs, give directly a red colour. To obtain this colour it muft be compounded different ways, as follows:-Take two parts, or two parts and a half (you may, however, take only one part,) of fulphat of iron and of fúlphat of alumine; fufe them together in their water of cryftallifation, and take care to mix them well together. Continue to heat them to complete drynefs; then increafe the fire fo as to bring the mixture to a red heat. The laft operation muft be performed in a reverberating furnace. Keep the mixture red until it has every where affumed. $a$ beautiful red colour, which you may afcertain by taking out a little of it from time to time, and fuffering it to cool in the air. You may then fee whether the matter is fufficiently red : to judge of this it muft be left to cool, becaufe while hot it appears black. The red oxyds of iron give: a red colour; but this colour is exceedingly fugitive; for, as foon as the oxyd of iron enters into fufion, the portion of oxygen which gives it its red colour leaves it, and it becomes black, 
yellow, or greenith. To preferve, therefore, the red colour of this oxyd in the fire, it mult be prevented from vitrifying, and abandoning its oxygen; which may be accomplifhed by the method I have indicated. I have tried a variety of different fubftances to give it this fixity, but none of them fucceeded except alum. The dofes of alum and fulphat of iron may be varied. The more alum you add, the paler will be the colour. Three parts of alum to one of fulphat of iron give a colour which approaches flefh colour. It is alum alfo. which gives this colour the property of becoming fixed at a very ftrong heat. This colour may be employed on raw: enamel: it has much more fixity than the purple, but not fo much as the blue of cobalt. It may be wafhed to carry off the fuperfluous faline matter, but it may be employed alfo without edulcoration; in that ftate it is even more fixed and more beautiful. - It does not require much flux; the flux which appeared to me to be beft fuited to it, is compofed of alum, minium, marine falt, and enamel fand. This flux mult be compounded in fuch a manner as to render it fufficiently. fufible for its objeet: from two to three parts of it are mixed with the colour. In general, three parts of flux are ufed for one of colour: but this dofe may, and ought to be varied according to the nature of the colour and the fhade of it required. Red calx of iron alone, when it enters into fufion with glafs, gives a colour which feems to be black; but if the colour be diluted with a fufficient quantity of glafs, it at laft becomes of a tranfparent yellow. Thus, the colour really produced by calx of iron combined with glafs is a yellow colour, but which being accumulated becomes fo dark that it appears black. In the procefs above given for making the red colour, the oxyd of iron does not fufe: and this is the effential point; for, if this colour is carried in the fire to vitrification, it becomes black, or yellowifh, and difappears if the coat be thin, and the oxyd of iron prefent be only in a fmall quantity.

\section{Yellow.}

Though yellow may be obtained in a direet manner, compound yellows are preferred; becaufe they are more certain in their effect, and more eafily applied than the yellow, 
which may be directly obtained from filver. The compound yellows are obtained in confequence of the fame principles as the red colour of iron. For this purpole we employ metallic oxyds, the vitrification of which muft be prevented by mixing with them other fubifances, fuch as refractory earths, or metallic oxyds difficult to be fufed.

The metallic calces which form the bafes of the yellow. colours are generally thofe of lead; as minium, the white calx of lead, or litharge, the white calx of antimony, called diaphoretic antimony: that called crocus metallorum is alfo employed. This regulus, pulverifed and mixed with white oxyd, gives likewife a yellow. The following are the different compofitions ufed : one part of the white oxyd of antimony, one of the white oxyd of lead (or two or three); thefe dofes are exceedingly variable; one part of alum, and one of fal-ammoniac. When thefe matters have been all pulverifed, and mixed well together, they are put in a veffel over a fire fufficient to fublinsate and decompofe the fal-ammoniac; and when the matter has affumed a yellow colour, the operation is finithed*. The calces of lead mixed in a fmall quantity either with filex or alumine, alfo with the pure calx of tin, exceedingly white, give likewife yellows. One part of the oxyd of lead is added to two, three, or four of the other fubftances above mentioned. 'In thefe different compofitions for yellow, you may ufe alfo oxyd of iron, either pure, or that kind which has been prepared with alum and vitriol of iron: you will then obtain different fhades of yellow. From what has been faid, you may vary thefe compofitions of yellow as much as you pleafe. Yellows require fo little flux, that one or two parts, in general, to one of the colour are fufficient; faline fluxes are improper for them, and efpecially thofe which contain nitre. They muft be ufed with fluxes compofed of enamel fand, oxyd of lead, and borax, without marine falt.

A yellow may be obtained alfo directly from filver. All thefe mixtures may be varied, and you may try others. For this purpofe you may ufe fulphat of filver, or any oxyd of that metal mixed with alumine or filex, or even with both.

* This in colour-hops is called Naples yellow. 
in equal quantities. The whole mult be gently heated until the yellow colour appear, and the matter is to be employed with the fluxes pointed out for yellows. Yellow of filver, like purple, cannot endure a ftrong heat: a nitric folution of filver may be precipitated by the ammoniacal phofphat of foda, and you will obtain a yellow precipitate, which may be ufed to paint in that colour with fluxes, which ought then to be a little harder.

Befides the methods above mentioned, the beft manner of employing the oxyd of filver is, in my opinion, to employ it pure : in that cafe, you do not paint, but ftain. It will be fufficient, then, to lay a light coating on the place which you with to fain yellow, and to heat the article gently to give it the colour. You muit not employ too ftrong a heat: the degree will eafly be found by practice. When the article has been.fufficiently heated, you take it from the fire and feparate the coating of oxyd, which will be found reduced to a regulus: you will then obferve the place which it occupied tinged of a beautiful yellow colour, without thicknefs. It is chiefly on tranfparent glafs that this procefs fucceeds beft. Very fine filver filings produce the fame effect: but what feemed to me to fucceed beft in this cafe, was fulphat of filver, well ground up with a little water, that it may be extended very fmooth. From what has been faid, it may readily be feen that this yellow muft not be employed like other colours; that it muft not be applied till the reft have been fufed; for, as it is exceedingly fufible, and ready to change, it would be injured by the other colours; and as the coating of filver which is reduced muft be removed, the fluxes would fix it, and prevent the poffibility of its being afterwards feparated. Working on glals is not attended with this inconvenience, becaufe the filver-yellow is applied on the oppofite fide to that on which the other colours are laid.

\section{Green.}

Green is obtained directly from the oxyd of copper. All the oxyds of copper.are good: they require little flux, which even muft not be too fufible: one part or two of flux will be fufficient for one oxyd. This colour agrees with all the fluxes, the faline as well as the metallic; which tends to vary 
a little the thades. I have already pointed out the method of employing thefe oxyds on raw enamel: were not that method only followed in this cafe, the oxyd of copper would extend, and fpread itfelf, like a cloud, beyond the limits precribed for it.

A mixture of yellow and bluc is alfo ufed to produce green. Thiofe who paint figures or portraits employ glafs compofed in this manner; but thofe who paint glazed veffels, eithet earthen-ware or porcelain, employ in general copper green.

Independently of the beautiful green colour produced by oxydated copper, it produces alfo a very beautiful red colour; but $I$ do not know that it is employed on enamel. This beautiful red colour, produced by copper, is exceedingly fugitive. The oxyd of copper gives red only when it contains very little oxygen, and approaches near to the ftate of a re. gulus. Notwithftanding the difficulty of employing this oxyd for a red colour, a method has been found to ftain tranfparent glafs with different thades of a very beautiful red colour by means of calx of copper. The procefs is as follows: You do not employ the calx of copper pure, but add to it calx of iron, which for that purpofe muft not be too much calcined; you add alfo a very fmall quantity of calx of copper to the mafs of glafs which you are defirous of tingeing. This glafs at firft muft have only a very flight tinge of green, inclining to yellow. When the glafs has that colour you make it pafs to red, and even a very dark red, by mixing with it red tartar in powder, and even tallow. You muft mix this matter well in the glafs, and it will affume a very dark red colour. The glafs fwells up very much by this addition. Before it is worked it muft be fuffered to fettle, and become compact; but as foon as it has fully affumed the colour it muft be immediately worked, for the colour does not remain long, and even often difappears while working; but it may be reftored by heating the glafs at the flame of a lamp. It is exceedingly difficult to make this colour well; but when it fucceeds it is very beautiful, and has a great deal of fplendour. By employing the cal $x$ of copper alone for the proceffes above mentioned you will obtain, when you fucceed well, a red frmitar to the moft beautiful carmine. The calx of iron ohanges 
the red into vermilion, according to the quantity added. If we had certain proceffes for making this colour, we fhould obtain all the thades of red from pure red to orange, by ufing, in different proportions, the oxyd of copper and that of iron. The calx of copper fufes argil more eafily than filex : the cafe is the fame with calx of iron. If you fufe two or three parts of argil with one of the oxyd of copper, and if the heat be fufficient, you will obtain a very opake enamel, and of a vermilion red colour : the oxyd of copper paffes from red to green through yellow; fo that the enamel of copper, which becomes red at a ftrong heat, may be yellow with a weaker heat. The fame effect may be produced by deoxydating copper in different degrees : this will be effected according as the heat is more or lefs violent. The above compofition might, I think, be employed to give a vermilion red colour to porcelain. The heat of the porcelain furnace ought to be of fufficient ftrength to produce the proper effect.

The calx of iron fufed alfo with argil in the fame proportions as the calx of copper, gives a very beautiful black. Thefe proportions may, however, be varied.

\section{Blue.}

Blue is obtained from the oxyd of cobalt. It is the moft fixed of all colours, and becomes equally beautiful with a weak as with a ftrong heat. The blue produced by cobalt is more beautiful the purer it is, and the more it is oxydated. Arfenic does not hurt it. The faline fluxes which contain nitre are thofe beft fuited to it: you, add a little alfo when you employ that flux which contains a little calcined borax or glafs of borax, though you may employ it alfo with that flux alone.

But the flux which, according to my experiments, gives to cobalt blue the greateft fplendour and beauty, is that compofed of white glafs (which contains no metallic calx), of borax, nitre, and diaphoretic antimony well wafhed. When this glafs is made for the purpole of being employed as a flux for blue, you may add lefs of the white oxyd of antimony : a fixth of the whole will be fufficient. 


\section{Violet.}

Black calx of manganefe, employed with faline fluxes, gives a very beautiful violet. By varying the fluxes, the thade of the colour may alfo be varied: it is very fixed as long as it retains its oxygen. The oxyd of manganefe may produce different colours; but for that purpofe it will be neceffary that we thould be able to fix its:oxygen in it in different proportions. How to effect this, as far as I know, has never yet been difcovered.

Thefe are all the colours obtained from metals. From this it is evident that fomething ftill remains to be difcovered We do not know what might be produced by the oxyds of platina, tungiten, molybdena, and nickel : all thefe oxyds are ftill to be tried; each of them muft produce a colour, and perhaps red, which is obtained neither directly nor with facility from any of the metallic fubftances formerly known and hitherto employed.

\section{GENERAL REMARKS.}

Thofe who paint on enamel, on earthen-ware, porcelain, \&c. muft regulate the fufibility of the colours by the moft tender of thofe employed, as for example, the purple. When the degree which is beft fuited to purple has been found, the otber lefs fufible colours may be fo regulated, (by additions of flux, when it is neceflary to fufe all the colours at the fame time, and at the fame degree of heat.

You may paint alfo in enamel without flux; but all the colours do not equally ftand the heat which muft be employed. If the enamel, however, on which you paint be very fufble, they may all penetrate it. This manner of painting gives-no thicknefs of colour; on the contrary, the colours fink into the enamel at the places where the tints are ftrongeft. To make them penetrate, and give them luftre, a pretty ftrong fire will be neceflary to foften the enamel and bring it to a ftate of fufion. This method cannot be practifed but on enamel compofed with fand, which I call enamel fand, as already mentioned. It may be readily feen, alfo, that the colours and enamel capable of enduring 
the greateft heat, will be the molt folid, and the leaft liable to be changed by the air. An account of the method of employing and baking enamel may be found in various works, and may be learned alfo by feeing the operations of enamellers.

\section{On a new fulminating Mercury. By EDWARD Howard, Efq. F.R.S.*}

\section{SECTION I.}

I HE mercurial preparations which fulminate, when mixed with fulphur, and gradually expofed to a gentle heat, are well known to chemifts : they were difcovered, and have been fully defcribed, by Mr. Bayent.

MM. Brugnatelli and Van Mons have likewife produced fulminations by concuffion, as well with nitrat of mercury and phofphorus, as with phofphorus and mof other. nitrats $¥$. Cinnabar, likewife, is amongft the fubftances which, according to MM. Fourcroy and Vauquelin, detonate by concuffion with oxymuriat of potafh $\S$.

Mr. Ameilon had, according to Mr. Berthollet, obferved, that the precipitate obtained from nitrat of mercury by oxalic acid fufes with a hiffing noife $\|$.

* From Tranfadtions of the Royal Society of Londan for 1800 .

Section

+ Opufcules Cbimiques de Bayen, Tom. I. p. 346 , and note in P. $344^{\circ}$

+ Annalcs de Cbintie, Tom. XXVII. p. 74 and 79.

$\S$ Ibid. Tom. XXI. p. ${ }_{2}{ }_{3} 8$.

If This fact has been mifreprefented in theintroduetion to a work entitled The Chemical Principies of the Metallic Arts, by W. Richardon, Surgeon, F.A.S. Sc. (page lwii.) The author, fpeaking of the acid of forrel, fays, " Klaproth of Berlin precipitated a nitrous folution of mercury with acid of wood-forrel neutralifed with vegetable alkali. The white precipitate, well wafhed and dried, produced a fulminating noife not inferior to that of fulminating gold. Acid of fugar, perfectly neutralifed by vegetable alkali, produced the fame precipitate, which, on expofure to heat, exhibited the fame fulminating power." I muft confefs, I have not been able to produce any fuch fulmination. Mro Richardon has moreover given this fuppofed difcovery to Mr. Klaproth; whereas Mr. Berthollet, when quoting the fact to which I fuppofe Mr. Richardfon intended to allude, obferves, "Qu'on avoit déjà donné le nom d'argent VoI. VII. 